\title{
DIGLOSIA
}

Volume 1, Nomor 1 (Februari 2018)

ISSN 2615-725X (Print)

Halaman 45-52

eISSN 2615-8655 (Online)

\section{BUDAYA AGRARIS DALAM KONSEP IDIOM BAHASA INDONESIA: KAJIAN ANTROPOLINGUISTIK}

\author{
Syamsul Rijal \\ Universitas Mulawarman \\ Pos-el: rijalpaddaitu@yahoo.com
}

\begin{abstract}
Language cannot be separated from culture. In fact, language is the cultural expression of a nation. An agrarian culture in Indonesian has undergone internalization, giving birth to new words and phrases. The results of this study show several words and phrases which are idioms in Indonesian with the process of internalization of agrarian culture. The words and phrases of the agrarian culture can be found in agricultural terms, for example lahan basah, membanting tulang, memeras keringat, panen, mencairkan, and others. These words and phrases have blended in people's minds and expressed everyday culture. Who knows who started and where it came from. However, the Indonesian language user community has accepted these terms as ancestral cultural heritage. Understanding idioms seems difficult if you only understand the meaning of conventions from Indonesian speakers. The semantic load contained in the concept of idioms is too long a derivative chain. Therefore, this paper bridges Indonesian language users to understand the concept of Indonesian idioms which is an internalization of the Indonesian agrarian culture itself.
\end{abstract}

Keywords: idiom, agrarian culture, antropolinguistics

\begin{abstract}
ABSTRAK
Bahasa memang tidak bisa dipisahkan dari budaya. Bahkan, bahasa merupakan ekspresi budaya suatu bangsa. Budaya agraris dalam bahasa Indonesia sudah mengalami internalisasi sehingga melahirkan berbagai kata dan frasa baru. Hasil penelitian ini menunjukkan beberapa kata dan frasa yang merupakan idiom dalam bahasa Indonesia dengan proses internalisasi budaya agraris. Kata dan frasa dari budaya agraris tersebut dapat ditemukan dalam istilah pertanian, misalnya lahan basah, membanting tulang, memeras keringat, panen, mencairkan, dan lainlain. Kata dan frasa tersebut telah membaur dalam benak masyarakat dan mengekspresikan budaya sehari-hari. Entah siapa yang memulai dan dari mana munculnya. Akan tetapi, masyarakat pengguna bahasa Indonesia telah menerima istilah-istilah tersebut sebagai warisan budaya nenek moyang. Memahami idiom sepertinya sulit jika hanya memahami makna konvensi dari para penutur bahasa Indonesia. Beban semantik yang terkandung dalam konsep idiom terlalu panjang rantai turunannya. Oleh karena itu, tulisan ini menjembatani pemakai bahasa Indonesia untuk memahami konsep idiom bahasa Indonesia yang merupakan internalisasi dari budaya agraris masyarakat Indonesia sendiri.
\end{abstract}

Kata Kunci: idiom, budaya agraris, antropolinguistik 


\section{A. PENDAHULUAN}

Bahasa dan budaya adalah dua hal yang tidak bisa dipisahkan. Meskipun demikian, sebagian ahli antropologi memasukkan bahasa sebagai salah satu unsur budaya (Koentjaraningrat, 2009). Akan tetapi, dalam praktiknya, bahasa memiliki peranan penting dalam menjaga kelestarian budaya. Hal ini disebabkan oleh adanya fungsi bahasa sebagai alat komunikasi yang digunakan untuk menyimpan, menjelaskan, dan bahkan mewariskan budaya tersebut.

Dalam kerangka kerja etnografi, para antropolog membagi budaya dalam tujuh unsur, yakni sistem bahasa, sistem teknologi, sistem mata pencaharian, organisasi sosial, sistem pengetahuan, sistem religi, dan kesenian (Koentjaraningrat, 1979). Artinya, memang bahasa merupakan pendukung atas kekokohan satu kebudayaan. Setiap peradaban tinggi yang ada dunia pasti memiliki sistem bahasa yang mapan, dengan penggunaan aksara yang mampu menerjemahkan segala ekspresi budaya suatu etnis.

Ekspresi budaya itulah yang banyak dijumpai dalam sistem bahasa suatu etnis atau masyarakat. Seperti bahasa Indonesia, di dalamnya banyak kosa kata yang menyimpan ekspresi budaya masyarakat Indonesia . Dari sekian banyak ekspresi tersebut, konsep atau bentuk idiom tampak menarik diteliti lebih jauh. Bentuk idiom dalam bahasa Indonesia banyak meminjam istilah pertanian atau budaya agraris masyarakat Indonesia.

Istilah tersebut kemudian digunakan secara lintas ilmu dalam keperluan satu disiplin ilmu. Misalnya, pekerjaan yang harus diselesaikan secara teratur, rutin, dan berat dikatakan menggarap sesuatu. Padahal, kata menggarap awalnya hanya digunakan untuk menggarap sawah pertanian. Bentuk-bentuk seperti kata menggarap sudah dipergunakan secara umum oleh masyarakat dalam bidang apapun, tanpa mempertimbangkan lagi sejarah penggunaan kata tersebut. Hal inilah yang akan dijelaskan lebih lanjut dalam bagianbagian berikutnya.

Untuk menjelaskan idiom-idiom tersebut, diperlukan bantuan beberapa disiplin ilmu linguistik serta turunan dan terapan-terapannya. Oleh karena itu, di bawah ini dijelaskan bagian-bagian dari ilmu linguistik tersebut.

\section{B. LANDASAN TEORI \\ 1. Semantik}

Sebelum sampai terapan ilmu linguistik dan antropologi, kajian semantik harus dilewati untuk melihat bentuk atau konsep makna yang melapisi sistem idiom. Semantik atau biasa disebut ilmu makna atau studi tentang makna kata (Ullman, 2014:1) merupakan ilmu yang tidak bisa dilupakan dalam mengkaji bahasa, utamanya perubahan makna kata. Dalam komunikasi, bahasa selalu memiliki peran utama karena mengandung konsep makna yang merupakan subtansi dari inti komunikasi. Makna konseptual merupakan unsur yang paling penting dalam komunikasi linguistik (Leech, 1997:52). Proses komunikasi tidak boleh terjebak dengan satu makna karena kadang-kadang maknanya tidak menunjukkan arti sebenarnya. Hal ini terjadi karena bahasa memiliki hubungan makna secara sosial (Palmer, 1989:7) dengan masyarakat, termasuk hubungan erat dengan budaya masyarakat pemakai bahasa.

Makna bahasa dalam setiap kata sering berkaitan erat dengan makna kata lain atau memiliki relasi secara sosiologi, antrapologi, atau psikologi. Hal ini disebut oleh Pateda (2010:41) sebagai konsep kemandirian kata atau melalui relasi dengan kata lain. Dalam konteks budaya agraris, beberapa kata dan frasa memunculkan makna baru setelah mengalami relasi panjang melalui sejarah peradaban manusia. Kata dan frasa tersebut telah diterima dan digunakan 
sampai sekarang oleh masyarakat pemakai bahasa di Indonesia.

\section{Idiomatikal}

Penyimpangan makna kata sering terjadi setelah kata tersebut mengalami afiksasi. Biasanya disebut penyimpangan gramatikal dan lazim terjadi pada setiap bahasa. Penyimpangan gramatikal terjadi bukan hanya pada tingkat kata, tetapi juga pada tingkat frasa dan klausa (Chaer, 2006:76).

Pada tingkatan kata, kata menggalakkan memiliki makna yang berbeda dengan kata merapikan, membersibkan, dan mengalabkan. Konfiks me-kan pada ketiga kata tersebut bermakna 'membuat jadi rapi, membuat jadi bersih, membuat jadi kalah'. Berbeda dengan kata menggalakkan, konfiks me-kan membentuk makna kata galak menjadi 'menggiatkan' atau 'mengaktifkan'. Konsep makna dalam kata menggalakkan ini dianggap bentuk penyimpangan makna gramatikal dan diterima sebagai istilah idiom.

Selain itu, konsep idiom sebenarnya merupakan bentuk lanjutan dari makna konotasi yang pada awalnya memiliki makna terikat. Akan tetapi, proses penggunaan idiom tersebut yang sudah lama dalam masyarakat akhirnya dianggap sebagai kata atau frasa yang memiliki makna bebas. Dengan demikian, perjalanan konsep idiom seolah-olah dari makna yang terikat konteks kemudian menjadi makna yang bebas konteks.

\section{Antropolinguistik}

Melihat bahasa lewat budaya atau sebaliknya, mengamati budaya lewat bahasa sering menjadi hal yang tumpang tindih. Sebagian ahli membedakan antara antropologi linguistik dan linguistik antropologi. Namun, berkaca pada penggunaan istilah sosiolinguistik, psikolinguistik, dan neurolinguistik, bentuk antropolinguistik-lah yang paling tepat (Sibarani, 2015:2). Dalam tulisan ini, antropolinguistik bekerja dalam kerangka kebudayaan agraris untuk menelusuri makna konsep idiom dalam bahasa Indonesia. Idiom-idiom tersebut dianalisis secara antropolinguistik untuk melihat proses internalisasi budaya agraris di dalamnya.

Ada tiga pokok penekanan kajian antropolinguistik, yakni perfomansi, indeksikalitas, dan partisipasi (Duranti dalam Sibarani, 2015:3). Salah satu penekanan tersebut, yakni konsep perfomansi yang memahami bahasa sebagai suatu tindakan, kegiatan, dan proses komunikatif. Intinya, bahasa menyimpan sumber-sumber kultural yang tidak bisa dipahami secara terpisah dari perfomansi atau pertunjukan kegiatan bahasa tersebut (Sibarani, 2015:3). Hal ini sejalan dengan yang dikatakan oleh Hermansyah (2016:9) bahwa antropolinguistik juga menggambarkan mengenai inspirasi intelektual yang berasal dari hubungan interaksional perspektif interaksional dan pemikiran manusia. Pemikiran manusia Indonesia sebagian tercermin dalam bahasa yang diperspektifkan dari budaya agrarisnya.

Garis besar kerangka kerja antropolinguistik adalah bagaimana bahasa merepresentasikan dunia (Supatra, 2017:11) dengan persepsi atau pandangan yang berbeda-beda. Persepsi inilah yang melahirkan kata dan frasa yang memunculkan makna idiom. Budaya pertanian atau budaya agraris di Indonesia termasuk salah satu cara pandang masyarakat yang banyak mempersepsikan dunia lewat bahasa. Hal-hal inilah yang akan dikaji lebih jauh dalam tulisan ini.

\section{METODE PENELITIAN}

Penelitian ini dikerjakan secara deskriptif kualitatif dengan mengumpulkan beberapa istilah atau idiom sebagai data yang akan dikaji. Data tersebut ditemukan dari beberapa bacaan dan juga sebagian diperoleh dari kamus. 
Data yang telah dikumpulkan kemudian dianalisis melalui kajian antropolinguistik.

\section{HASIL PENELITIAN}

Ada beberapa data (idiom) dalam bahasa Indonesia yang secara antropolinguistik merupakan bentuk internalisasi dari budaya agraris masyarakat Indonesia. Idiom-idiom tersebut akan dianalisis sesuai kerangka kerja kajian antropolinguistik.

\section{(1) lahan basah}

Frasa laban basah secara denotasi bermakna 'mengandung air atau barang cair'; dan 'belum dikeringkan' atau 'masih basah'. Namun, secara konotasi, frasa laban basab bermakna 'banyak mendatangkan keuntungan (uang dan sebagainya) (KBBI V). Pada makna konotasi di atas, frasa laban basah telah mengalami perubahan makna secara asosiasi. Asosiasi tersebut muncul dari budaya agraris dalam bidang pertanian masyarakat Indonesia. Profesi mayoritas masyarakat Indonesia sebagai petani membuat frasa lahan basah ini mudah diterima sebagai bentuk makna konotasi 'banyak mendatangkan keuntungan (uang dan sebagainya)'.

Kebiasaan masyarakat Indonesia bercocok tanam sangat memahami jenis tanah atau lahan yang subur untuk ditanami. Jenis tanah yang subur biasanya berada di wilayah yang curah hujannya teratur karena kebutuhan air selalu tercukupi. Sebaliknya, tanah yang kering, gersang, dan jarang curah hujannya dianggap tanah atau lahan yang tidak subur dan tentu tidak tepat digunakan untuk bercocok tanam.

Dengan demikian, makna idiom dalam frasa lahan basah ini tidak muncul dan tidak diterima begitu saja, tetapi memang frasa yang berasal dari budaya agraris atau bercocok tanam yang secara mayoritas dipahami oleh masyarakat Indonesia. Frasa lahan basab ini merupakan hasil internalisasi budaya agraris yang berasosiasi dan melekat dalam kebiasaan memahami jenis pekerjaan, yakni pekerjaan yang cepat mendatangkan keuangan (Rijal, 2017).

\section{(2) membanting tulang}

Frasa membanting tulang merupakan bentuk konotasi dari frasa bekerja keras (KBBI V). Secara denotasi, frasa membanting tulang dapat bermakna 'tulang (di luar diri manusia) yang dibanting oleh manusia'. Jika frasa membanting tulang secara denotasi bermakna 'membanting tulang sendiri', tentu hal itu sangat sulit dilakukan bagi manusia. Oleh karena itu, perbuatan membanting tulang dianggap sebagai perbuatan atau pekerjaan yang sangat keras secara fisik.

Makna 'bekerja keras' yang disematkan dalam frasa membanting tulang tidak muncul begitu saja. Frasa ini telah melewati proses kulturasi lokal dengan kebiasaan berbahasa masyarakat Indonesi secara umum yang banyak bekerja dengan mengandalkan aktivitas fisik secara berat. Aktivitas fisik tersebut rata-rata merupakan aktivitas pertanian yang dimiliki bangsa Indoensia sebagai negara yang berbudaya agraris.

Frasa membanting tulang akhirnya menjadi idiom yang telah diterima masyarakat Indonesia dengan makna 'bekerja keras'. Aktivitas bertani merupakan salah satu budaya agraris yang memerlukan tenaga berat. Rasa berat itulah yang memunculkan istilah membanting. Sementara, tenaga yang berat biasanya dikeluarkan melalui pergerakan tulang dan otot pada manusia. Jadi, idiom membanting tulang sebenarnya bentuk paduan ekspresi antara pekerjaan yang sangat berat dengan ungkapan bahasa yang berusaha menggambarkan beratnya pekerjaan itu.

\section{(3) peras keringat/memeras keringat}


Frasa peras keringat atau memeras keringat merupakan internalisasi budaya agraris di Indonesia. Intinya, frasa ini bermakna 'bekerja keras'; sama dengan makna frasa membanting tulang. Masyarakat Indonesia yang pada umumnya bekerja sebagai petani lebih banyak memahami sebuah pekerjaan serius sebagai sesuatu yang identik dengan keluarnya tenaga disertai cucuran keringat. Padahal, bekerja keras pada era modern tidak selamanya identik dengan tenaga berat dan keluarnya keringat. Karena, beberapa pekerjaan dapat diselesaikan dalam ruangan yang dingin dan tentunya tidak perlu mengeluarkan keringat.

\section{(4) sesuap nasi}

Secara lengkap, frasa sesuap nasi biasanya ditambah menjadi mencari sesuap nasi yang artinya 'mencari rezeki'. Mengapa dalam budaya Indonesia, sesuatu yang berkaitan dengan rezeki sering diidentikkan dengan nasi? Karena, budaya masyarakat Indonesia pada umumnya mengonsumsi nasi sebagai makanan pokok. Frasa sesuap nasi ini juga merupakan frasa yang lahir dari internalisasi budaya agraris masyarakat Indonesia.

Begitu pentingnya nasi dalam kehidupan masyarakat Indonesia, budaya makan nasi sudah merasuk secara psikologi ke dalam sistem bahasa masyarakat Indonesia. Makanya, jika mendengar kalimat bahasa Indonesia saya sedang makan, itu berarti objek yang dimakan adalah nasi. Sebab, jika seseorang makan selain nasi, pasti kalimatnya diperjelas dengan objek tambahan, misalnya saya sedang makan roti.

Oleh karena itu, usaha-usaha yang digeluti setiap hari masyarakat Indonesia, selalu berkaitan dengan usaha mencari rezeki, makan, minum, dan kebutuhan lainnya. Akan tetapi, dominasi budaya agraris membuat kata nasi atau frasa mencari sesuap nasi dapat mewakili semua hal di atas sebagai konotasi dari bekerja untuk mendapat rezeki.

\section{(5) cair/mencairkan}

Salah satu makna kata mencairkan adalah 'menjadikan kenyataan (seperti menguangkan dana)'. Makna lain dari kata mencairkan juga dapat berarti 'memperbolehkan diambil kembali (simpanan uang di bank)'. Dalam sistem ilmu fisika, tentu dana atau uang merupakan sesuatu yang tidak bisa mencair karena merupakan zat padat. Akan tetapi, adanya makna kiasan atau konotasi dalam sistem semantik bahasa Indonesia membuat zat padat bisa mencair.

Dari mana asal mula benda padat berupa uang dapat disebut mencair? Budaya agraris di Indonesia, terutama bertani padi sangat memerlukan banyak pasokan air. Menanam padi sangat bergantung dari persedian air, baik air hujan maupun irigasi. Olehnya itu, menanam padi sudah identik dengan air. Sementara, padi sebagai tanaman penghasil beras yang juga merupakan sumber makanan pokok masyarakat Indonesia dianggap sebagai tanaman yang paling penting di antara tanaman lain. Oleh sebab itu, melimpahnya air ditandai sebagai jalan dekat bertambahnya rezeki.

Jadi, air, padi, dan rezeki sudah menyatu sebagai sesuatu yang bisa mendatangkan kesejahteraan. Termasuk uang merupakan sesuatu yang dapat mensejahterakan. Dengan demikian, uang yang bisa diambil atau dibelanjakan sering disebut cair, seperti mengalirnya air memasuki sawah-sawah pertanian lalu mencairkan tanah kering menjadi lumpur hingga siap ditanami padi.

\section{(6) panen}

Kata panen sering dijadikan kata kiasan untuk menggambarkan makna tentang perolehan sesuatu yang melimpah 
dan mudah. Kata panen awalnya hanya digunakan dalam bidang pertanian saat menuai atau mengambil secara masif hasil tanaman yang sudah siap dikonsumsi. Istilah panen ini kemudian digunakan untuk hal-hal yang membawa keuntungan dan rezeki yang diperoleh dengan cara mudah. Bahkan, kata panen semakin melebar maknanya saat ini; misalnya frasa panen pujian. Oleh karena itu, kata panen juga dapat bermakna 'sesuatu yang banyak'. Namun di balik semua itu, kita perlu ketahui bahwa penggunaan kata panen dengan berbagai makna kiasan merupakan internalisasi dari budaya agraris masyarakat Indonesia yang mayoritas berprofesi sebagai petani.

\section{(7) menyingsingkan}

Secara kiasan, menyingsingkan bermakna 'bekerja keras'. Misalnya pada kalimat menyingsingkan lengan baju, dapat bermakna 'siap-siap bekerja keras'. Lantas dari mana hubungan antara bekerja keras dengan menyingsingkan lengan baju. Kata menyingsingkan sudah menjadi idiom dalam bahasa Indonesia sehingga memiliki makna turunan dari budaya masyarakat Indonesia. Para petani di sawah biasanya menyingsingkan atau menggulung lengan bajunya jika turun ke sawah untuk bekerja. Hubungan makna ini terus terpelihara hingga menurunkan idiom menyingsingkan dengan makna 'bekerja keras'. Jadi, menyingsingkan merupakan bentuk internalisasi budaya agraris masyarakat Indonesia yang dimaknai sebagai ungkapan untuk siap-siap bekerja keras.

\section{E. PENUTUP}

Dalam bahasa Indonesia, sebenarnya masih banyak kata dan frasa idiom yang merupakan bentuk internalisasi dari budaya agraris. Namun, hanya tujuh kata dan frasa yang ditampilkan dan dianalisis dalam tulisan ini karena keterbatasan ruang dalam satu judul artikel. Memahami idiom sepertinya sulit jika hanya memahami makna konvensi dari para penutur bahasa Indonesia. Beban semantik yang terkandung dalam konsep idiom terlalu panjang rantai turunannya. Oleh karena itu, tulisan ini menjembatani pemakai bahasa Indonesia untuk memahami konsep idiom bahasa Indonesia yang merupakan internalisasi dari budaya agraris masyarakat Indonesia sendiri.

\section{DAFTAR PUSTAKA}

Chaer, A. (2006). Bahasa Indonesia dalam Masyarakat: Kajian Semantik. Jakarta: PT Rineka Cipta.

Hermansyah, W. (2016). Terminologi Rumah Adat dalam Loka Sumbawa: Suatu Kajian Antropolinguistik. Retorika: Jumal Ilmu Bahasa, 2(2). Diperoleh dari https://ejournal.warmadewa.ac.id /index.php/jret/article/view/62

Kementerian Pendidikan dan Kebudayaan Republik Indonesia. (2018). Kamus Besar Babasa Indonesia Edisi Kelima (KBBI V). Online.

Koentjaraningrat. (1979). Sejarah Teori Antropologi I. Jakarta: UI Press.

Koentjaraningrat. (2009). Pengantar Ilmu Antropologi. Edisi Revisi. Jakarta: PT Rineka Cipta.

Leech, G. (1997). Semantics. Surakarta: Sebelas Maret University Press.

Palmer, F. R. (1989). Semantik. Kuala Lumpur: Universiti Sains Malaysia dan Dewan Bahasa dan Pustaka Kementerian Pendidikan Malaysia.

Pateda, M. (2010). Semantik Leksikal. Jakarta: Rineka Cipta.

Rijal, S. (2017). "Lahan Basah: Internalisasi Budaya Agraris". Diakses dari http://www.unmul.ac.id/post/la han-basah--internalisasi-budaya- 
agraris-1506929902.html

Desember 2017).

Sibarani, R. (2015). Pendekatan Antropolinguistik dalam Kajian Tradisi Lisan. Retorika: Jurnal Ilmu Bahasa, 1(1). Diperoleh dari https://ejournal.warmadewa.ac.id /index.php/jret/article/view/9

Supatra, H. (2017). Pokok-pokok Bahasan

Kebahasaan dalam Kajian
Antropologi Bahasa. Nusa: Jurnal Ilmu Bahasa dan Sastra, 12(2). Diperoleh dari https://ejournal.undip.ac.id/inde x.php/nusa/article/view/15661

Ullman, S. (2014). Pengantar Semantik. Cetakan Kelima. Yogyakarta: Pustaka Pelajar. 
